\title{
Synthesis and Characterization of Ultrasmall $\mathrm{MgFe}_{2} \mathrm{O}_{4}$ Nanoparticles down to the Quantum Dot Scale
}

\author{
H.S. Refai, A. Hashhash, M. Yehia* \\ Reactor Physics Department, Nuclear Research Center, Egyptian Atomic Energy Authority, , Cairo, Egypt
}

\begin{tabular}{|c|c|}
\hline ARTICLE & ABSTRACT \\
\hline Article history: & \multirow{8}{*}{$\begin{array}{l}\text { Three polycrystalline } \mathrm{MgFe}_{2} \mathrm{O}_{4} \text { ferrite nanoparticles; MF1, MF2, and MF3 were } \\
\text { prepared by the sol gel autocombustion method. The structural, elastic, and magnetic } \\
\text { properties were studied using X-ray powder diffraction (XRD), Fourier-transform } \\
\text { infrared spectroscopy (FTIR) measurements, and vibrating sample magnetometer } \\
\text { (VSM). X-ray powder diffraction patterns confirm the formation of the pure cubic spinel } \\
\text { phase. The particle size (D) was determined and found to be } 3 \mathrm{~nm}, 37 \mathrm{~nm} \text {, and } 48 \mathrm{~nm} \text { for } \\
\text { MF1, MF2, and MF3, respectively. The elastic parameters showed a weak dependence } \\
\text { on the particle size. The magnetic hysteresis loops indicated that the saturation } \\
\text { magnetization }\left(\mathrm{M}_{\mathrm{s}} \text { ) and coercivity }\left(\mathrm{H}_{\mathrm{c}} \text { ) decreased with decreasing the particle size (D). }\right.\right. \\
\text { The values of the coercivity are size-dependent, which suggests that the prepared } \\
\text { samples have a single magnetic domain structure. The temperature dependence of the } \\
\text { magnetic parameters was investigated for the samples, whereas, the saturation } \\
\text { magnetization and coercivity were increased with decreasing temperature. }\end{array}$} \\
\hline Received: $24^{\text {th }}$ July 2021 & \\
\hline Accepted: $1^{\text {st }}$ Nov. 2021 & \\
\hline Keywords: & \\
\hline $\mathrm{MgFe}_{2} \mathrm{O}_{4}$ nanoparticles, & \\
\hline Elastic properties, & \\
\hline Superparamagnetism, & \\
\hline & \\
\hline
\end{tabular}

\section{INTRODUCTION}

Spinel ferrite nanoparticles have several industrial and biomedical applications [1,2]. The structural, elastic, electrical, and magnetic properties of these materials are strongly affected by the chemical composition and microstructure, which are very sensitive to the preparation methods and conditions [3,4]. For spinel ferrite nanoparticles, changing the preparation conditions yields different particle sizes and morphology. Below a critical particle size $\left(D_{\mathrm{sp}}\right)$ and for a specific range of temperatures, the formation of magnetic domain walls is not energetically favorable. In this case, the thermal energy is higher than the energy barrier related to the magnetocrystalline anisotropy, and hence the magnetic moment of every single particle can fluctuate causing high magnetization values around the blocking temperature $\left(\mathrm{T}_{\mathrm{B}}\right)$, and the absence of coercivity $\left(\mathrm{H}_{\mathrm{c}}\right)$ [5]. In spinel ferrites with the formula $\mathrm{MFe}_{2} \mathrm{O}_{4}$, the oxygen ions are closely packed into a face center cubic lattice having two different sites; the tetrahedral (A) site and octahedral (B) site [3]. The magnesium ferrite is a soft magnetic material that crystalizes in partial inverse spinel structure $\left(\mathrm{Mg}_{1-\delta} \mathrm{Fe}_{\delta}\right)\left[\mathrm{Mg}_{\delta} \mathrm{Fe}_{2-\delta}\right] \mathrm{O}_{4}$ and $\delta$ is the degree of inversion [6].
$\mathrm{MgFe}_{2} \mathrm{O}_{4}$ is produced conventionally by solid state reactions of magnesium and iron oxides or carbonates mixtures at temperatures of about 1100 Celsius or above. However, this method brings some disadvantages such as loss of reactants, phase separation, heterogeneous particle size and shape distribution and high energy consumption [7]. To overcome this problem, different preparation techniques have been used, e.g.; coprecipitation [8], sol-gel [9], microemulsions [10], reverse micelle [11], combustion method [12], mechanosynthesis [13], high energy milling [14], electrospinning [15] and hydrothermal synthesis [16].

In this paper, the structural, elastic, and magnetic properties of the $\mathrm{MgFe}_{2} \mathrm{O}_{4}$ ferrite nanoparticles were synthesized via the autocombustion method. The particle size of the prepared samples was controlled by changing the preparation conditions. The purity of the samples was confirmed using X-ray powder diffraction (XRD) measurements. The influence of the reduced particle size on the elastic parameters and the magnetic properties were investigated by means of the Fourier-transform infrared spectroscopy (FTIR) and vibrating sample magnetometer (VSM) measurements. 


\section{EXPERIMENTAL}

The precursor powders of $\mathrm{MgFe}_{2} \mathrm{O}_{4}$ were prepared through sol-gel auto combustion method at different $\mathrm{pH}$ values $(5,7 \& 8)$. The acid regulator in the solutions was replaced with and alkaline regulator ammonia water. All raw materials were purchased from Sigma Aldrich, $\mathrm{Mg}\left(\mathrm{NO}_{3}\right)_{2}$ and $\mathrm{Fe}\left(\mathrm{NO}_{3}\right)_{3} . \mathrm{NH}_{2} \mathrm{Ch}_{2} \mathrm{COOH}$ was added to the solution with a known stoichiometric ratio to the nitrates. The glycine/nitrate $(\mathrm{G} / \mathrm{N})$ ratio was calculated according to the propellant chemistry principle. The general equation for sol-gel auto combustion of $\mathrm{MgFe}_{2} \mathrm{O}_{4}$ is as follows:

$$
\begin{aligned}
\mathrm{Mg}\left(\mathrm{NO}_{3}\right)_{2}+2 \mathrm{Fe}\left(\mathrm{NO}_{3}\right)_{3}+x \mathrm{NH}_{2} \mathrm{CH}_{2} \mathrm{COOH} & \\
& \rightarrow \mathrm{MgFe}_{2} \mathrm{O}_{4}+a \mathrm{~N}_{2}+b \mathrm{CO}_{2}+\mathrm{cH}_{2} \mathrm{O}
\end{aligned}
$$

According to the Propellant chemistry theory, the sum of oxidizing valence of nitrates is (-25) and the sum of reducing the valence of glycine is (9). Thus, the elemental stoichiometric coefficient $\left(\varphi_{e}\right)$ was calculated as follows:

$$
\varphi_{e}=\frac{\sum_{i=1}^{n} \text { oxidizing valence of nitrates }}{(-1) \sum_{i=1}^{n} \text { reducing valence of fuel }}
$$

From the equation: $\left(\varphi_{e}\right)=\frac{-40}{9}=4.44 \&$ the total nitrate molecule is 6.22 . Hence, we derived the stoichiometric $\mathrm{G} / \mathrm{N}$ ratio of $\frac{4.44}{6.22}=0.71$. From the obtained $\mathrm{G} / \mathrm{N}$ value, $\mathrm{x}, \mathrm{a}, \mathrm{b} \& \mathrm{c}$ were calculated

$x=\varphi_{e}=4.44, a=6.22, b=2 x=8.88, c=x \frac{b}{2}=19.71$.

Given the above mentioned values, the general equation of 1 becomes:

$\mathrm{Mg}\left(\mathrm{NO}_{3}\right)_{2}+2 \mathrm{Fe}\left(\mathrm{NO}_{3}\right)_{3}+4.44 \mathrm{NH}_{2} \mathrm{CH}_{2} \mathrm{COOH}$

$$
\rightarrow \mathrm{MgFe}_{2} \mathrm{O}_{4}+6.22 \mathrm{~N}_{2}+8.88 \mathrm{CO}_{2}+19.71 \mathrm{H}_{2} \mathrm{O}
$$

All the prepared $\mathrm{MgFe}_{2} \mathrm{O}_{4}$ samples were characterized using X-ray diffraction (XRD) (Philips X'pert multipurpose diffractometer) with $\mathrm{CuK}_{\alpha}$ radiation. The lattice parameter and particle size were calculated using the MAUD software [17]. Transmission electron microscope (TEM) images were performed using a JEOL 4010 device to study the particle size of the $\mathrm{MgFe}_{2} \mathrm{O}_{4}$ nanoferrites. The infrared spectra were recorded using Bruker Tensor 27 FTIR spectrometer in the range $250-1000 \mathrm{~cm}^{-1}$. Magnetic measurements on different $\mathrm{MgFe}_{2} \mathrm{O}_{4}$ samples were carried out at different temperatures by using a vibrating sample magnetometer (VSM) up to an applied magnetic field of $20 \mathrm{kG}$.

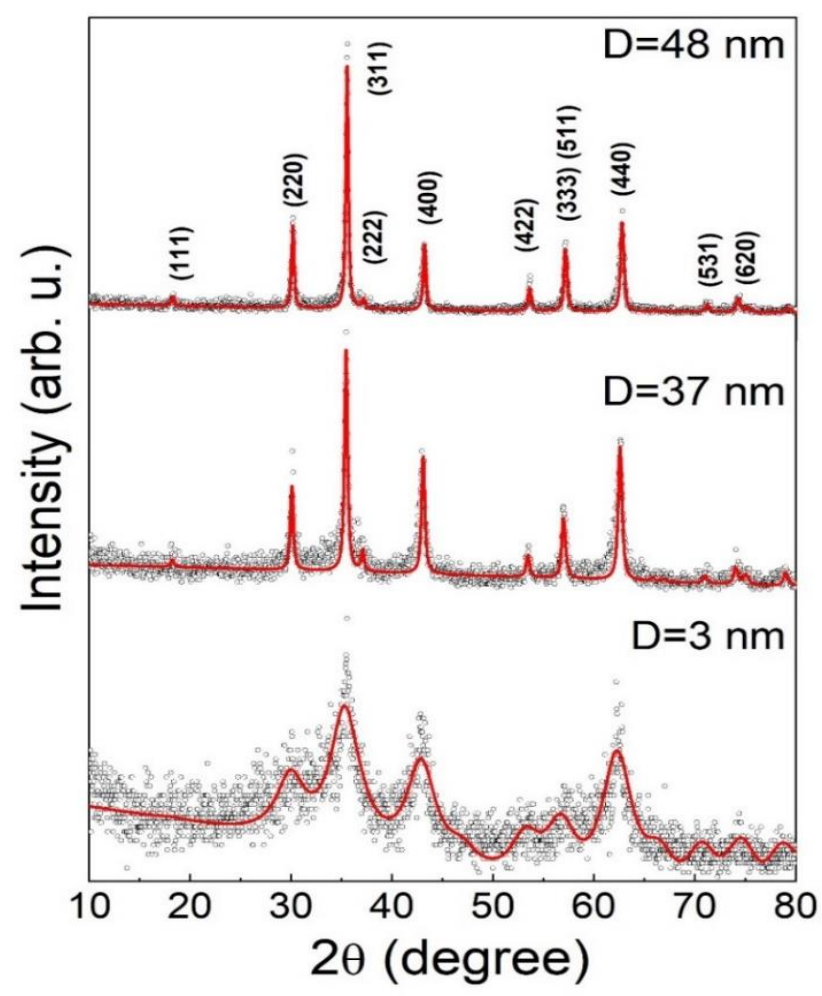

Fig. (1): XRD patterns of different $\mathrm{MgFe}_{2} \mathrm{O}_{4}$ samples and the average particle size (D) is indicated for each sample. Red lines represent Rietveld refinement using MAUD

\section{RESULTS AND DISCUSSION}

\subsection{X-ray powder diffraction Measurements}

$\mathrm{X}$-ray diffraction patterns for $\mathrm{MgFe}_{2} \mathrm{O}_{4}$ nanoferrites with different grain sizes are shown in Figure 1. XRD measurements confirm that the prepared samples crystalize in a single-phase face centered cubic (fcc) with the space group Fd-3m. The obtained XRD patterns were fitted using MAUD software and the lattice constant $(a)$ and the particle size (D) of different $\mathrm{MgFe}_{2} \mathrm{O}_{4}$ nanoparticles were determined and listed in Table 1 and shown in figure 2. A clear signature of the reduced particle size was spotted in a gradual broadening of the diffraction peaks with decreasing $D$ from $48 \mathrm{~nm}, 37 \mathrm{~nm}$ to $3 \mathrm{~nm}$. The observed differences in the particle size can be attributed directly to the differences in preparation methods. As illustrated in Table 1, the lattice parameter (a) values are relatively close for all the prepared samples, these results were observed before in the case of $\mathrm{NiFe}_{2} \mathrm{O}_{4}$ nanoparticles [3,18]. Such behavior is expected since the chemical composition is the same for all samples and the decreased particle size would cause a minor change in the cation distribution. From the lattice parameter, the distance between the magnetic ions in the A-sites and the B- sites can be calculated as [19]: 


$$
\begin{aligned}
& L_{A}=\frac{\sqrt{3}}{4} a \\
& L_{B}=\frac{\sqrt{2}}{4} a
\end{aligned}
$$

In this case, $\mathrm{L}_{\mathrm{A}}$, and $\mathrm{L}_{\mathrm{B}}$ represent the hopping lengths in the $\mathrm{A}$ and the B- sites, respectively. As shown in figure 2(b, c), the hopping lengths for both sites decrease gradually with increasing the particle size, which will support the magnetic interactions between $\mathrm{Fe}^{3+}$ ions in both sites. The density $\left(\rho_{\mathrm{x}}\right)$ can be determined from the lattice parameter as:

$$
\rho_{x}=\frac{8 M}{N_{A} a^{3}}
$$

$\mathrm{M}$ is the molecular weight and $\mathrm{N}_{\mathrm{A}}$ is the Avogadro's number. The density increases gradually with increasing the particle size since $a$ is decreased with increasing D.

From Williamson-Hall (W-H) plots, the particle size (D) and microstrain ' $\varepsilon$ ' can be determined. $\beta$ is the broadening of XRD peaks and $\lambda$ the XRD wavelength
$\left(\mathrm{CuK}_{\alpha}\right.$ radiation with $\left.\lambda=1.5418\right)$, the Williamson-Hall $(\mathrm{W}-\mathrm{H})$ equation is expressed as [20]:

$$
\beta \cos \theta=\frac{\lambda k}{D}+4 \varepsilon \sin \theta
$$

where $k=0.9$. As shown in figure $3, \mathrm{XRD}$ peaks $\left(\begin{array}{lll}3 & 1 & 1\end{array}\right)$, (4 00 ), and (4 40 ) of the three samples were fitted using Gaussian line profile and from the fitting, $\theta$ and $b$ values were determined. Figure 4 shows Williamson and Hall's plot for different $\mathrm{MgFe}_{2} \mathrm{O}_{4}$ samples. The $\mathrm{W}-\mathrm{H}$ plots are shown in figure 4 , and the obtained values of the particle size and microstrain are listed in Table 1. The obtained values of $\mathrm{D}_{\mathrm{W}-\mathrm{H}}$ are very close to the particle size values obtained from the Maud fitting (Table 1). Figure (2d) illustrates the values of microstrain, whereas a significant change from a negative value of $\varepsilon$ for MF1 (3nm) to positive values for the samples with larger particle sizes (MF2 and MF3) was observed. The negative values of the microstrain suggest a compressive strain for MF1, whereas, positive values refer to the occurrence of $\varepsilon$ tensile strain [21].

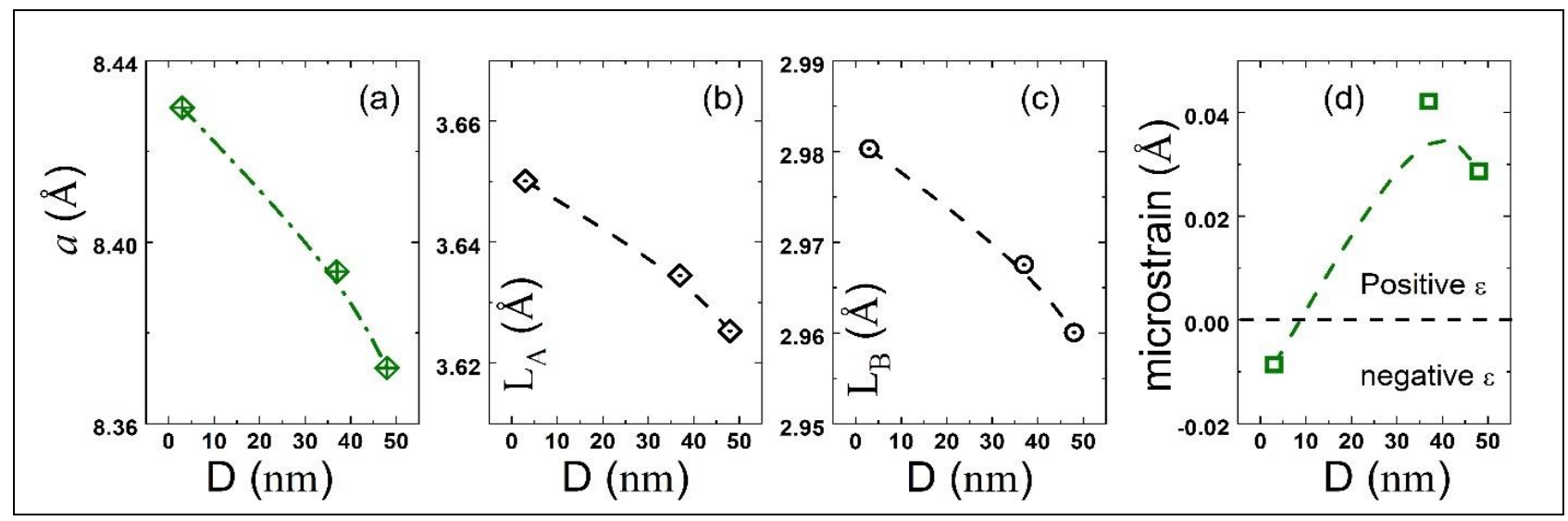

Fig. (2): a) The lattice parameter $a$, The hopping lengths b) $L_{A}$ for the tetrahedral site, c) $L_{B}$ for the octahedral site, d) Microstrain $\&$ for different $\mathrm{MgFe}_{2} \mathrm{O}_{4}$ nanoparticles

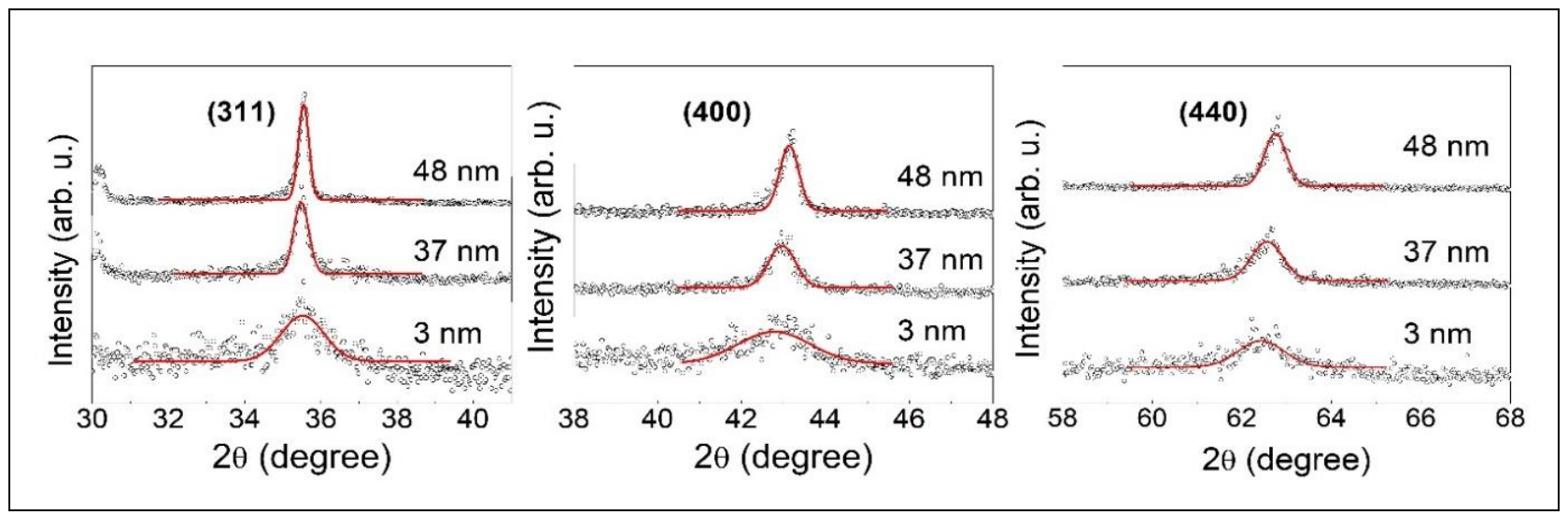

Fig. (3): Gaussian fitting of (311), (400), and (440) XRD peaks for different $\mathrm{MgFe}_{2} \mathrm{O}_{4}$ nanoparticles 
Table (1): Particle size (D, $\left.D_{W-H}\right)$, lattice constant $(a)$, hopping lengths $\left(L_{A}\right.$, and $\left.L_{B}\right)$, microstrain $\varepsilon$, and density $\left(\rho_{x}\right)$ of different $\mathrm{MgFe}_{2} \mathrm{O}_{4}$ samples

\begin{tabular}{cccccccc}
\hline Sample & $\begin{array}{c}\mathbf{D} \\
(\mathbf{n m})\end{array}$ & $\begin{array}{c}\mathbf{D}_{\mathbf{W}-\mathbf{H}} \\
(\mathbf{n m})\end{array}$ & $\begin{array}{c}\boldsymbol{a} \\
(\mathbf{\AA})\end{array}$ & $\begin{array}{c}\mathrm{L}_{\mathrm{A}} \\
(\mathbf{\AA})\end{array}$ & $\begin{array}{c}\mathrm{L}_{\mathrm{B}} \\
(\mathbf{\AA})\end{array}$ & $\begin{array}{c}\boldsymbol{\varepsilon} \\
(\mathbf{\AA})\end{array}$ & $\begin{array}{c}\rho_{\mathrm{x}} \\
\left(\mathbf{g ~ c m}^{-\mathbf{1}}\right) \mathbf{x} \mathbf{1 0}\end{array}$ \\
\hline $\mathbf{M F 1}$ & 3 & 3.63 & 8.42959 & 3.65012 & 2.98031 & -0.00864 & 4.44 \\
$\mathbf{M F 2}$ & 37 & 33.59 & 8.39352 & 3.6345 & 2.96756 & 0.04213 & 4.49 \\
$\mathbf{M F 3}$ & 48 & 45.94 & 8.37234 & 3.6253 & 2.96004 & 0.02863 & 4.53 \\
\hline
\end{tabular}
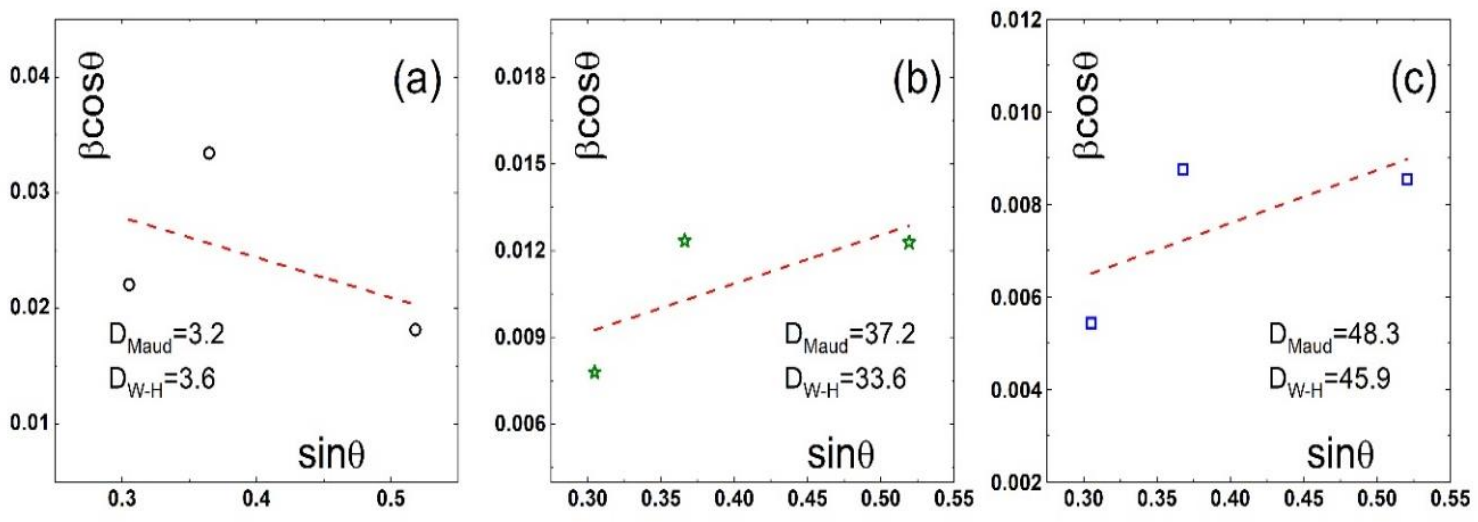

Fig. (4): W-H plots for different $\mathrm{MgFe}_{2} \mathrm{O}_{4}$ samples

\subsection{TEM measurements}

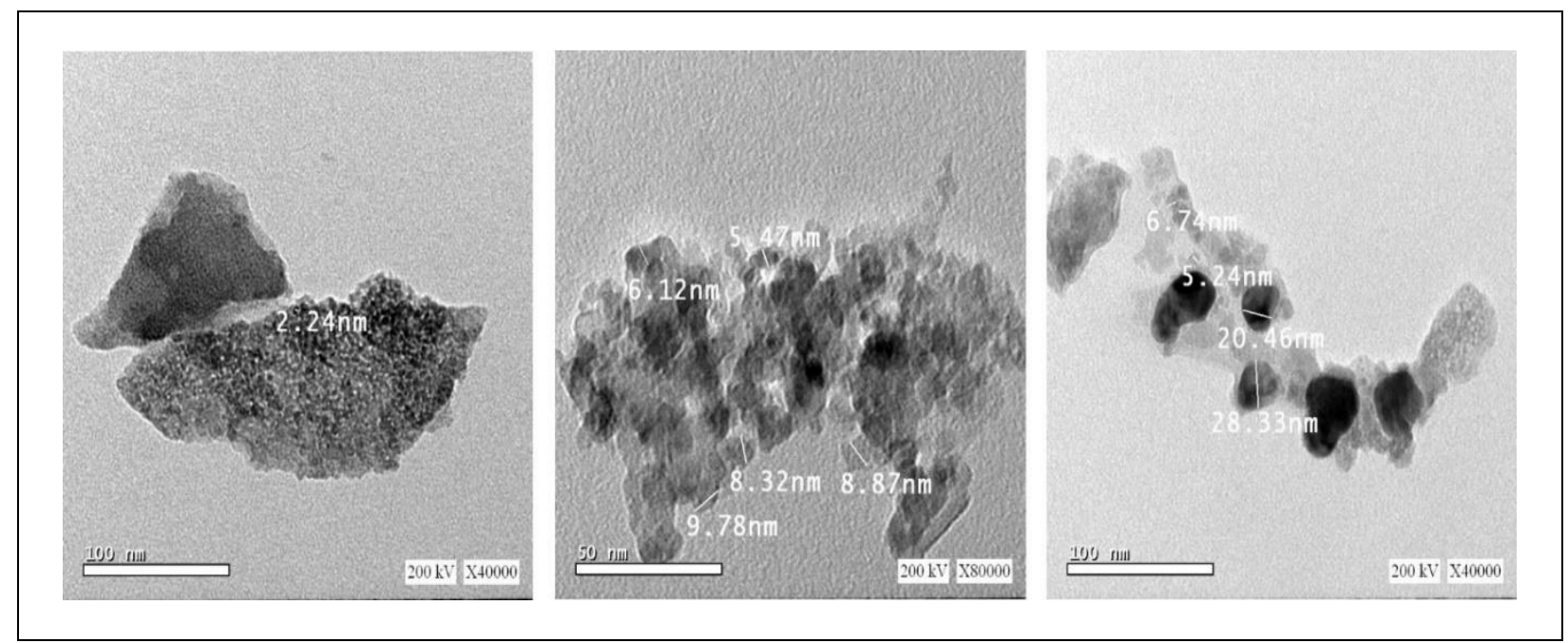

Fig. (5): TEM images of different $\mathrm{MgFe}_{2} \mathrm{O}_{4}$ samples

The transmission electron microscope (TEM) micrographs for the $\mathrm{MgFe}_{2} \mathrm{O}_{4}$ samples are presented in Fig. 5. The nanoparticles have a spherical shape with a particle size close to that calculated from the XRD measurements. The particle size of the MF1 sample shown by TEM image is extremely small. 


\subsection{Fourier transform-infrared analysis}

FTIR measurements of different $\mathrm{MgFe}_{2} \mathrm{O}_{4}$ samples in the wavenumber range of $250-1000 \mathrm{~cm}^{-1}$ are shown in Figure (6-a). In general, two regions of vibrational frequency are fundamental in the FTIR spectra of spinel ferrites. The region around $400 \mathrm{~cm}^{-1}$ is related to the intrinsic stretching vibration of the transition metals ions in the octahedral B-sites. The other region around 500 $\mathrm{cm}^{-1}$ is related to the intrinsic stretching vibration of the transition metals ions in the tetrahedral A-sites [22]. Higher energy is needed for the bond $(\mathrm{Fe}-\mathrm{O})$ stretching vibration mode occupying the tetrahedral site than that octahedral site, as the bond length at A-site is shorter than B-site [23]. In addition, different atoms at a particular site are not vibrating at a single frequency, where the probability of IR absorption is different. Consequently, different frequencies can be obtained. In our case, the difference in the atomic mass of $\mathrm{Mg}$ and $\mathrm{Fe}$ atoms is related to the splitting of the bands. Furthermore, the correlation between the vibrations of the tetrahedral complexes and that of the octahedral complexes is expected $[22,25]$.

All the vibrational frequencies related to both crystallographic sites are listed in Table (2). The force constant per atom, bulk modulus (B), the longitudinal sound wave velocity $\left(\mathrm{V}_{1}\right)$, the transverse sound wave velocity $\left(\mathrm{V}_{\mathrm{t}}\right)$, mean elastic wave velocity $\left(\mathrm{V}_{\mathrm{m}}\right)$, rigidity modulus (G), Young's modulus (E), Debye temperature $\left(\theta_{\mathrm{D}}\right)$, and the lattice energy $(\mathrm{U})$ can be calculated using the following equations [22-26]:

$$
\begin{gathered}
k_{t}=7.62 \times M_{A} \times v_{t}^{2} \times 10^{-7} \mathrm{~N} / \mathrm{m} \\
k_{o}=10.62 \times \frac{M_{B}}{2} \times v_{o}^{2} \times 10^{-7} \mathrm{~N} / \mathrm{m} \\
\mathrm{B}=\frac{\mathrm{k}}{a} \\
v_{l}=\left[\frac{9 B}{5 \rho_{x}}\right]^{\frac{1}{2}} \\
v_{t}=\left[\frac{3 \mathrm{~B}}{5 \rho_{x}}\right]^{\frac{1}{2}} \\
v_{m}=\left[\frac{1}{3}\left(\frac{2}{v_{t}^{3}}+\frac{1}{v_{l}^{3}}\right)\right]^{\frac{-1}{3}} \\
G=\rho_{x} v_{t}^{2} \\
E=\frac{9 \mathrm{BG}}{3 \mathrm{~B}+\mathrm{G}} \\
\theta_{D}=\frac{h c v_{a v}}{k} \\
\mathrm{U}=-3.108\left(M v_{m}\right) \times 10^{-12}
\end{gathered}
$$

For all the samples, the calculated values of these parameters are listed in Tables (2 and 3). The average molecular weights of cations in A- and B- sites are $\mathrm{M}_{\mathrm{A}}$, and $\mathrm{M}_{\mathrm{B}}$. $\mathrm{A}$ partial inverse spinel structure $\left(\mathrm{Mg}_{0.1} \mathrm{Fe}_{0.9}\right)_{\mathrm{A}}\left[\mathrm{Fe}_{1.1} \mathrm{Mg}_{0.9}\right]_{\mathrm{B}} \mathrm{O}_{4}$ was considered in calculating the average molecular weights of the tetrahedral and octahedral sites [27].
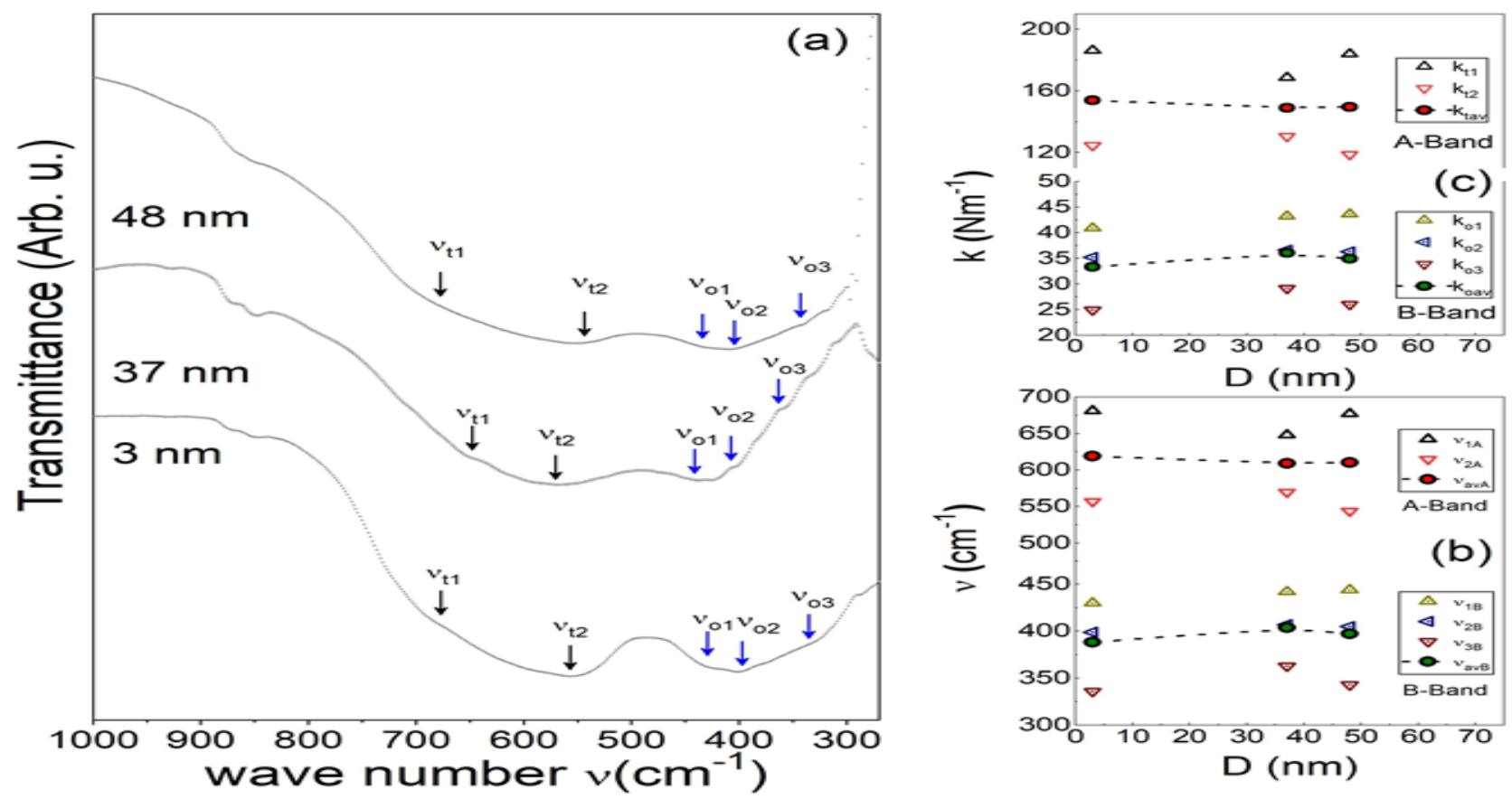

Fig. (6): a) FTIR spectra, b) vibrational frequencies (v), and c) force constants (k) for different $\mathrm{MgFe}_{2} \mathrm{O}_{4}$ nanoparticles 


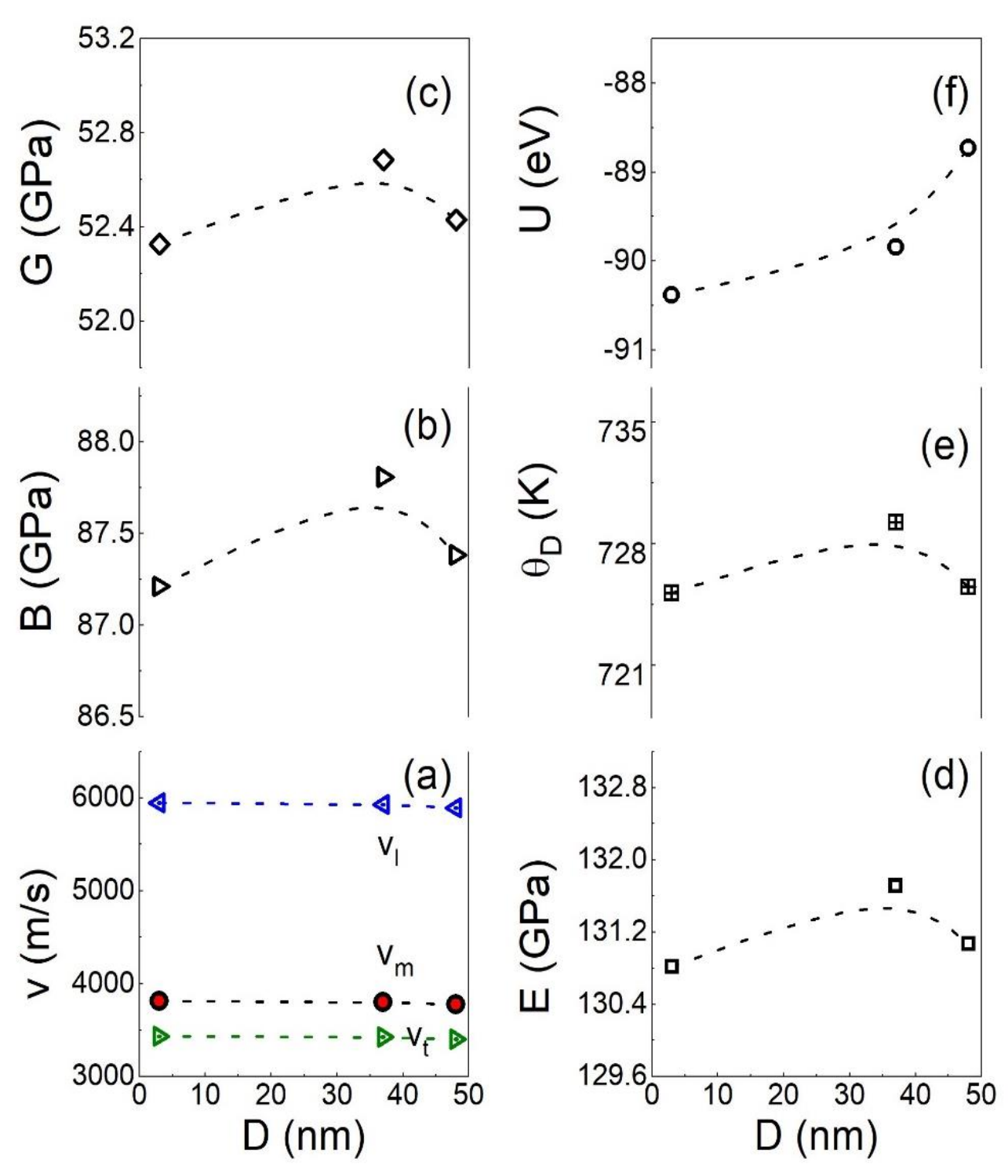

Fig (7): a) Elastic wave velocities ( $V_{l}, V_{t}$ and $V_{m}$ ), elastic constants: b) Bulk modulus $B$, c) rigidity modulus $G$, and d) Young's modulus E, e) the Debye temperature $\left(\theta_{D}\right)$, and f) the lattice energy (U) for different $\mathrm{MgFe}_{2} \mathrm{O}_{4}$ samples

The obtained force constants for the studied samples are shown in Fig. (6-c). In general, the interaction between the cations located in the A-site and the surrounding oxygen anions (due to the shorter bond) is stronger than the interaction between the cations located in the B-site and the surrounding oxygen anions (longer bond). Accordingly, the force factor of the tetrahedral site $\left(\mathrm{k}_{\mathrm{t}}\right)$ is higher than that of the octahedral site $\left(\mathrm{k}_{\mathrm{o}}\right)$. The vibration of atoms changes by changing the bond length, charge, mass, and size of the ions forming this bond. Consequently, the force constant involved in these vibrations will be affected by the same factors. As illustrated from the XRD measurements, small changes in the lattice parameters were observed. On the other hand, changing the preparation conditions and decreasing the particle size of different $\mathrm{Mg}$-ferrite samples may cause differences in the distribution of $\mathrm{Fe}^{3+}$ and $\mathrm{Mg}^{2+}$ ions between $\mathrm{A}$ and B sites. Such differences in the cation distributions will logically affect the vibration frequencies and force constant as shown in Fig.(6-c). 
For all the samples, the calculated values of the bulk modulus (B), the longitudinal sound wave velocity $\left(\mathrm{V}_{\mathrm{l}}\right)$, the transverse sound wave velocity $\left(\mathrm{V}_{\mathrm{t}}\right)$, mean elastic wave velocity $\left(\mathrm{V}_{\mathrm{m}}\right)$, rigidity modulus $(\mathrm{G})$, Poisson's ratio (P), Young's modulus (E) and Debye temperature $\left(\theta_{\mathrm{D}}\right)$ are listed in Table (3) and Figure (7). The elastic wave velocities $V_{l}, V_{t}$, and $V_{m}$ are inversely proportional to the density $\left(\rho_{\mathrm{x}}\right)$. As illustrated in Table 1 , the density is increased with increasing D. This can explain the gradual decrease of the elastic wave velocities $\mathrm{V}_{\mathrm{l}}, \mathrm{V}_{\mathrm{t}}$, and $\mathrm{V}_{\mathrm{m}}$ with increasing the particles size D. The elastic moduli (B, $\mathrm{G}$, and E) directly proportional to force constant derived out of the vibrational frequency and inversely proportional to the lattice parameter calculated from the XRD measurements. The values of elastic moduli and the Debye temperature show weak dependence on the particle size. Interestingly, $\mathrm{B}, \mathrm{G} \mathrm{E}$, and $\theta_{\mathrm{D}}$ dependence on the particle size have relatively similar behavior to the microstrain. The changes in the particle size affect the grain boundaries and cause fine changes in the stiffness of the studied samples. The lattice energy is increasing with an increase in the particle size. Such behavior can be attributed to the changes in the lattice constant, which will decrease the atomic spacing and lower the lattice energy [26].

Table (2): Different vibrational frequencies (v), and force constants (k) of different $\mathrm{MgFe}_{2} \mathrm{O}_{4} \mathrm{Samples}$

\begin{tabular}{|c|c|c|c|c|c|c|c|c|c|c|c|c|c|c|}
\hline D & $v_{t 1}$ & $v_{t 2}$ & $v_{\text {tav }}$ & $v_{01}$ & $v_{02}$ & $v_{03}$ & $v_{\text {oav }}$ & $\mathbf{k}_{\mathbf{t} 1}$ & $\mathbf{k}_{\mathbf{t} 2}$ & $\mathbf{k}_{\mathrm{tav}}$ & $\mathbf{k}_{01}$ & $\mathbf{k}_{02}$ & $\mathbf{k}_{\mathbf{0 3}}$ & $\mathbf{k}_{\text {oav }}$ \\
\hline$(\mathbf{n m})$ & & & & $\left.\mathrm{cm}^{-1}\right)$ & & & & \multicolumn{7}{|c|}{$(\mathrm{N} / \mathrm{m})$} \\
\hline 3 & 681 & 557 & 619 & 430 & 399 & 336 & 388 & 186.2 & 124.6 & 153.8 & 40.9 & 35.2 & 25 & 33.4 \\
\hline 37 & 648 & 570 & 609 & 442 & 407 & 363 & 404 & 168.6 & 130.5 & 148.9 & 43.2 & 36.6 & 29.2 & 36.1 \\
\hline 48 & 677 & 544 & 610.5 & 444 & 405 & 343 & 397 & 184 & 118.8 & 149.7 & 43.6 & 36.3 & 26 & 34.9 \\
\hline
\end{tabular}

Table (3): Elastic wave velocities (V), elastic constants (B, G, and E), the Debye temperature ( $\left.\theta_{\mathrm{D}}\right)$, and the lattice energy (U) for different $\mathrm{MgFe}_{2} \mathrm{O}_{4}$ samples

\begin{tabular}{ccccccccc}
\hline $\begin{array}{c}\mathbf{D} \\
(\mathbf{n m})\end{array}$ & $\begin{array}{c}\mathbf{B} \\
(\mathbf{G p a})\end{array}$ & $\begin{array}{c}\mathbf{V}_{\mathbf{l}} \\
(\mathbf{c m} / \mathbf{s})\end{array}$ & $\begin{array}{c}\mathbf{V}_{\mathbf{t}} \\
(\mathbf{c m} / \mathbf{s})\end{array}$ & $\begin{array}{c}\mathbf{V}_{\mathbf{m}} \\
(\mathbf{G})\end{array}$ & $\begin{array}{c}\mathbf{G} \\
(\mathbf{G p a})\end{array}$ & $\begin{array}{c}\mathbf{E} \\
(\mathbf{G P a})\end{array}$ & $\begin{array}{c}\boldsymbol{\theta}_{\mathbf{D}} \\
(\mathbf{K})\end{array}$ & $\begin{array}{c}\mathbf{U} \\
(\mathbf{e v})\end{array}$ \\
\hline $\mathbf{3}$ & 87.21 & 5949 & 3435 & 3813 & 52.33 & 130.82 & 725.17 & -90.38 \\
$\mathbf{3 7}$ & 87.81 & 5931 & 3424 & 3802 & 52.69 & 131.71 & 729.25 & -89.84 \\
$\mathbf{4 8}$ & 87.38 & 5895 & 3403 & 3778 & 52.43 & 131.07 & 725.53 & -88.73 \\
\hline
\end{tabular}
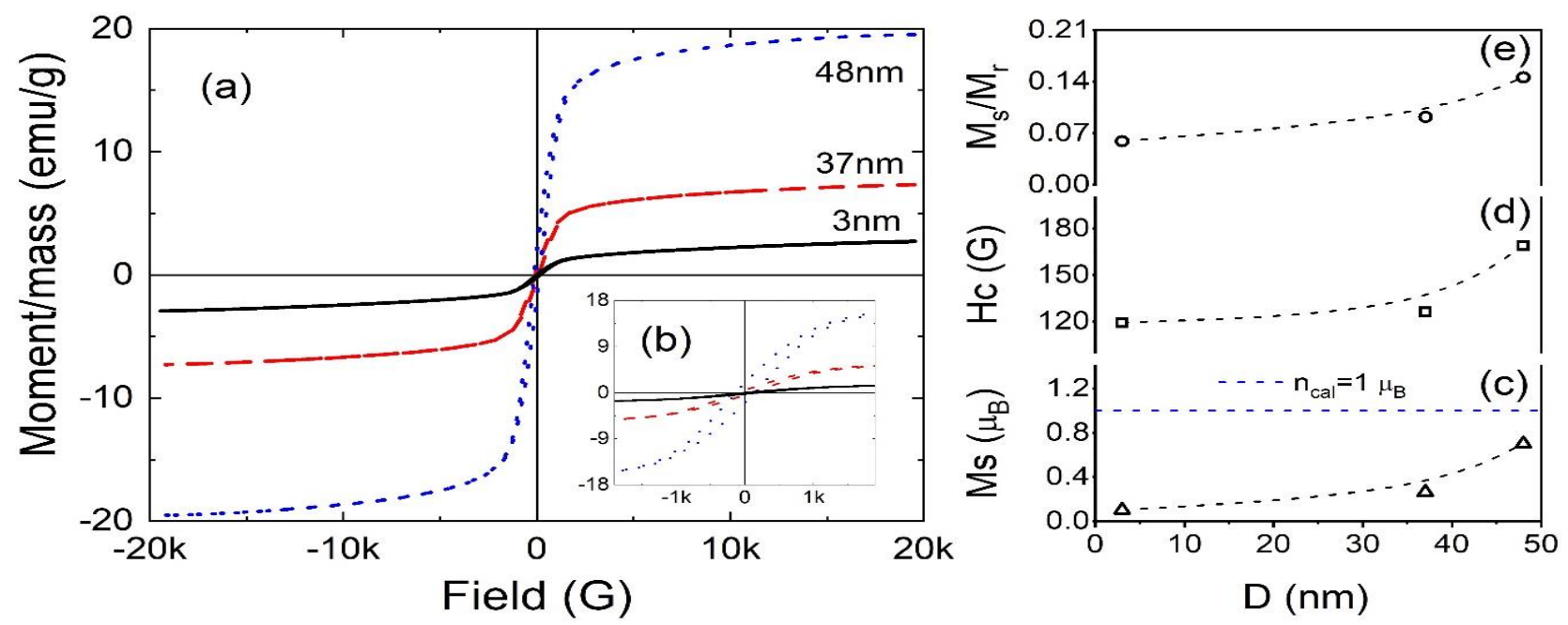

Fig. (8): a,b) Room temperature hysteresis loops, c) The observed saturation magnetization $\left.\left(\mathbf{M}_{\text {obs }}\right), d_{)}\right)$coercivity $\left(H_{c}\right)$, and e) the squareness ratio $\left(R^{2}=M_{r} / M_{s}\right)$ 


\subsection{Magnetic properties}

Figure 8 shows the vibrating sample magnetometer (VSM) measurements for different $\mathrm{Mg}$-ferrite nanoparticles at room temperature $(T=300 \mathrm{~K})$. The obtained magnetic parameters; the saturation magnetization $\left(\mathrm{M}_{\mathrm{s}}\right)$, coercivity $\left(\mathrm{H}_{\mathrm{c}}\right)$, remnant magnetization $\left(\mathrm{M}_{\mathrm{r}}\right)$, squareness $\mathrm{R}^{2}=\mathrm{M}_{\mathrm{r}} / \mathrm{M}_{\mathrm{s}}$, and saturation magnetization in Bohr magneton units for the three samples are presented in Table 4 and Figure (8). In general, the saturation magnetization and coercivity gradually decrease with decreasing the particle size D. The decreased $M_{s}$ for smaller particle size is attributed to the fact that the surface of the nanoparticles is composed of randomly oriented spins that repel the core spins to align the field direction and hence, these spins act as a dead layer with inconsiderable magnetization. Whereas, the size dependence of the coercivity can have two distinguished behaviors. For large particle sizes in the multidomain region, and above the single domain threshold $\left(D_{c}\right)$, the coercivity tends to increase gradually with decreasing particle size. On the other hand, below $\mathrm{D}_{\mathrm{c}}$, the behavior is inversed and $\mathrm{H}_{\mathrm{c}}$ decreases systematically for smaller particle sizes. Only at the superparamagnetic limit $\left(\mathrm{D}_{\mathrm{sp}}\right), \mathrm{H}_{\mathrm{c}}$ is expected to be zero. For the present samples, $\mathrm{H}_{\mathrm{c}}$ decreases with decreasing $\mathrm{D}$, which might indicate that the particle size of the studied samples is below the single domain limit $\mathrm{D}_{\mathrm{c}}$. This result is confirmed by the values of squareness, where it increases with increasing the particle size [28]. $\mathrm{M}_{\mathrm{s}}$ is given in Bohr magneton unit as:

$$
M_{\text {obs }}=\left(M_{s} \times M\right) / 5585
$$

The observed moment $\left(\mathrm{M}_{\mathrm{obs}}\right)$ are shown in Table (4) and Figure (8b). The magnetic properties of ferrites are mainly originated by A-A, A-B, and B-B magnetic superexchange interactions. According to Néel's Model, the magnetic moment $\mathrm{M}_{\mathrm{cal}}$ is formulated as:

$$
M_{\text {cal }}=M_{B}-M_{A}
$$

The tetrahedral moment $\mathrm{M}_{\mathrm{A}}$ and octahedral moment $\mathrm{M}_{\mathrm{B}}$ were calculated using the cation distribution $\left(\mathrm{Mg}_{0.1} \mathrm{Fe}_{0.9}\right)_{\mathrm{A}}\left[\mathrm{Fe}_{1.1} \mathrm{Mg}_{0.9}\right]_{\mathrm{B}} \mathrm{O}_{4}$ and the only magnetic ion is $\mathrm{Fe}^{3+}$ with a magnetic moment $5 \mu_{\mathrm{B}}$. In this case, $\mathrm{M}_{\text {cal }}$ will be $1 \mu_{\mathrm{B}}$. The field dependence of the magnetization $\mathrm{M}(\mathrm{H})$ can be described as [29]:

$$
M(H)=M_{S}\left(1-\frac{\mathrm{b}}{H^{2}} \ldots\right)+\chi_{0} H
$$

For a uniaxial symmetry, the coefficient b is expressed as:

$$
b=\frac{4}{15}\left(\frac{\mathrm{K}}{\mu_{0} M_{s}}\right)^{2}
$$

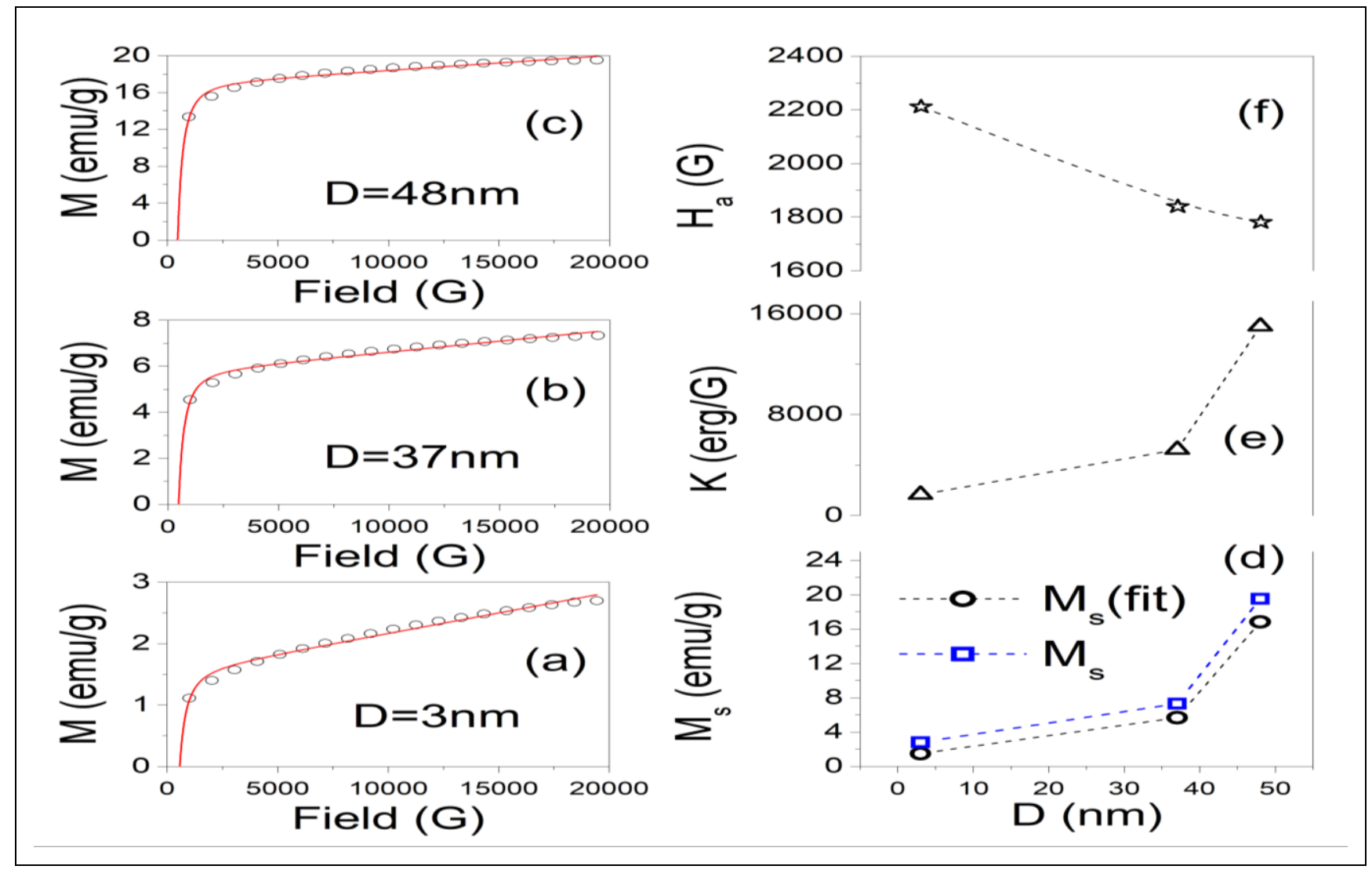

Fig. (9): a,b,c) The fitting of room temperature of $M(H)$ according to Eq. (18), d) Ms and Ms(fit), e) effective magnetic anisotropy constant $(\mathrm{K})$, and f) the anisotropy field $\left(\mathrm{H}_{\mathrm{a}}\right)$ for different $\mathrm{MgFe}_{2} \mathrm{O}_{4}$ samples 
$\mathrm{K}$ is the effective magnetic anisotropy constant. The anisotropy field $\left(\mathrm{H}_{\mathrm{a}}\right)$ is related to the saturation magnetization and $\mathrm{K}$ as:

$$
H_{a}=\frac{2 \mathrm{~K}}{\mu_{0} M_{s}}
$$

The fitting of $\mathrm{M}(\mathrm{H})$ of different $\mathrm{MgFe}_{2} \mathrm{O}_{4}$ nanoparticles is shown in Figure (9a-c), where the values of $\mathrm{K}$ and $\mathrm{H}_{\mathrm{a}}$ are presented in Table (4) and Figure (9c,d). As indicated in Table (4) and Figure (9b), considerable differences between the values of saturation magnetization calculated from the fitting (Eq. 18) and that obtained directly from the hysteresis loops. This difference can be explained by the factor $\chi_{0}$, which illustrates a linear paramagnetic contribution to the magnetic response. The paramagnetic contribution can be attributed to; i) paramagnetic intrinsic impurities, or/and ii) the ultra-small nanoparticles with superparamagnetic behavior. $\chi_{0}$ increases with increasing the particle size (Figure 10a). As shown in Figure (9e), $\mathrm{K}$ increases dramatically with increasing $\mathrm{D}$. Whereas, the anisotropy field gradually decreases with increasing the particle size. By increasing the particle size, a transition from a single domain to a multi domain system is expected. According to the present measurements, MF1, MF2, and MF3 have average particle sizes below the single domain limit $D_{c}$. However, by increasing D, and according to the particle size distribution within each sample, a considerable ratio of the particles may have $\mathrm{D}>\mathrm{D}_{\mathrm{c}}$. This will logically affect the values of the magnetic parameters and cause the increase of $\mathrm{M}_{\mathrm{s}}, \mathrm{H}_{\mathrm{c}}$, and $\mathrm{K}$.

The magnetic hysteresis loops at different temperatures $(\mathrm{T}=100 \mathrm{~K}, 150 \mathrm{~K}, 200 \mathrm{~K}, 250 \mathrm{~K}$, and $300 \mathrm{~K})$ for MF1 sample with $\mathrm{D}=3 \mathrm{~nm}$ are presented in Figure (11a). The magnetic parameters; $M_{s}, H_{c}, M_{r}$, and the squareness are listed in Table (5). The saturation magnetization, coercivity, and squareness ratio are increasing with decreasing the temperature. The $\mathrm{M}(\mathrm{H})$ curves were fitted using Eq. (16) (Figure 12) and the effective magnetic anisotropy constant (K) and anisotropy field $\left(\mathrm{H}_{\mathrm{a}}\right)$ have been calculated and listed in Table (5). $\chi_{0}$ increases with decreasing the temperature (Figure 10b), whereas $\mathrm{K}$ and $\mathrm{H}_{\mathrm{a}}$ are also increase with decreasing $\mathrm{T}$. This temperature dependence of the magnetic parameters may suggest that the MF1 sample has a particle size below the superparamagnetic limit $\mathrm{D}_{\mathrm{sp}}[5]$.

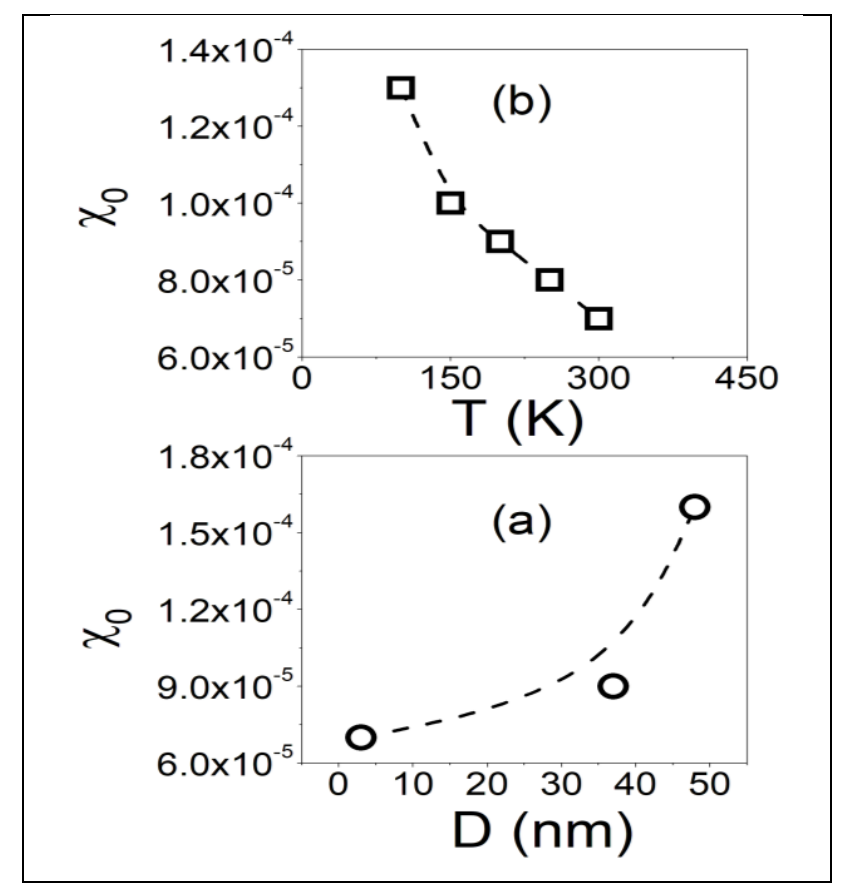

Fig. (10): The dependence of linear contribution of the magnetization $\left(\chi_{0}\right)$ on: a) The particle size at $300 \mathrm{~K}$, and b) temperature for the sample MF1 (3nm)

Table (4): The saturation magnetization $\left(M_{s}\right)$, coercivity $\left(H_{c}\right)$, remanent magnetization $\left(M_{r}\right)$, the squareness ratio $\left(\mathbf{R}^{2}=\mathbf{M}_{\mathrm{r}} / \mathbf{M}_{\mathrm{s}}\right)$, observed moment $\mathbf{M}_{\mathrm{obs}}$, and the parameters obtained from Eqs (16-18); $\mathbf{M}_{\mathrm{s}}$ (Fit), effective magnetic anisotropy constant $(\mathrm{K})$ and the anisotropy field $\left(\mathrm{H}_{\mathrm{a}}\right)$ for different $\mathrm{MgFe}_{2} \mathrm{O}_{4}$ samples

\begin{tabular}{|c|c|c|c|c|c|c|c|c|c|}
\hline Sample & $\begin{array}{c}\mathbf{M}_{\mathrm{s}} \\
(\mathrm{emu} / \mathrm{g})\end{array}$ & $\begin{array}{l}\mathbf{H}_{\mathbf{c}} \\
(\mathbf{G})\end{array}$ & $\begin{array}{c}M_{r} \\
(e m u / g)\end{array}$ & $\mathbf{R}^{2}=\mathbf{M}_{\mathrm{r}} / \mathbf{M}_{\mathrm{s}}$ & $\begin{array}{c}\mathbf{M}_{\mathrm{s}}(\mathbf{o b s}) \\
\left(\boldsymbol{\mu}_{\mathrm{B}}\right)\end{array}$ & $\begin{array}{l}M_{s}(\text { fit }) \\
(\mathrm{emu} / \mathrm{g})\end{array}$ & $\chi_{0}$ & $\begin{array}{c}K \\
(\operatorname{erg} / G)\end{array}$ & $\begin{array}{l}\mathbf{H}_{\mathbf{a}} \\
(\mathbf{G})\end{array}$ \\
\hline $3 \mathrm{~nm}$ & 2.8275 & 119.11 & 0.16684 & 0.05901 & 0.10125 & 1.51 & $7 \mathrm{E}-5$ & 1667 & 2212 \\
\hline $37 \mathrm{~nm}$ & 7.3157 & 126.01 & 0.67129 & 0.09176 & 0.26196 & 5.69 & $9 \mathrm{E}-5$ & 5233 & 1840 \\
\hline $48 \mathrm{~nm}$ & 19.535 & 168.84 & 2.8451 & 0.14564 & 0.69952 & 16.84 & $1.6 \mathrm{E}-4$ & 15001 & 1782 \\
\hline
\end{tabular}




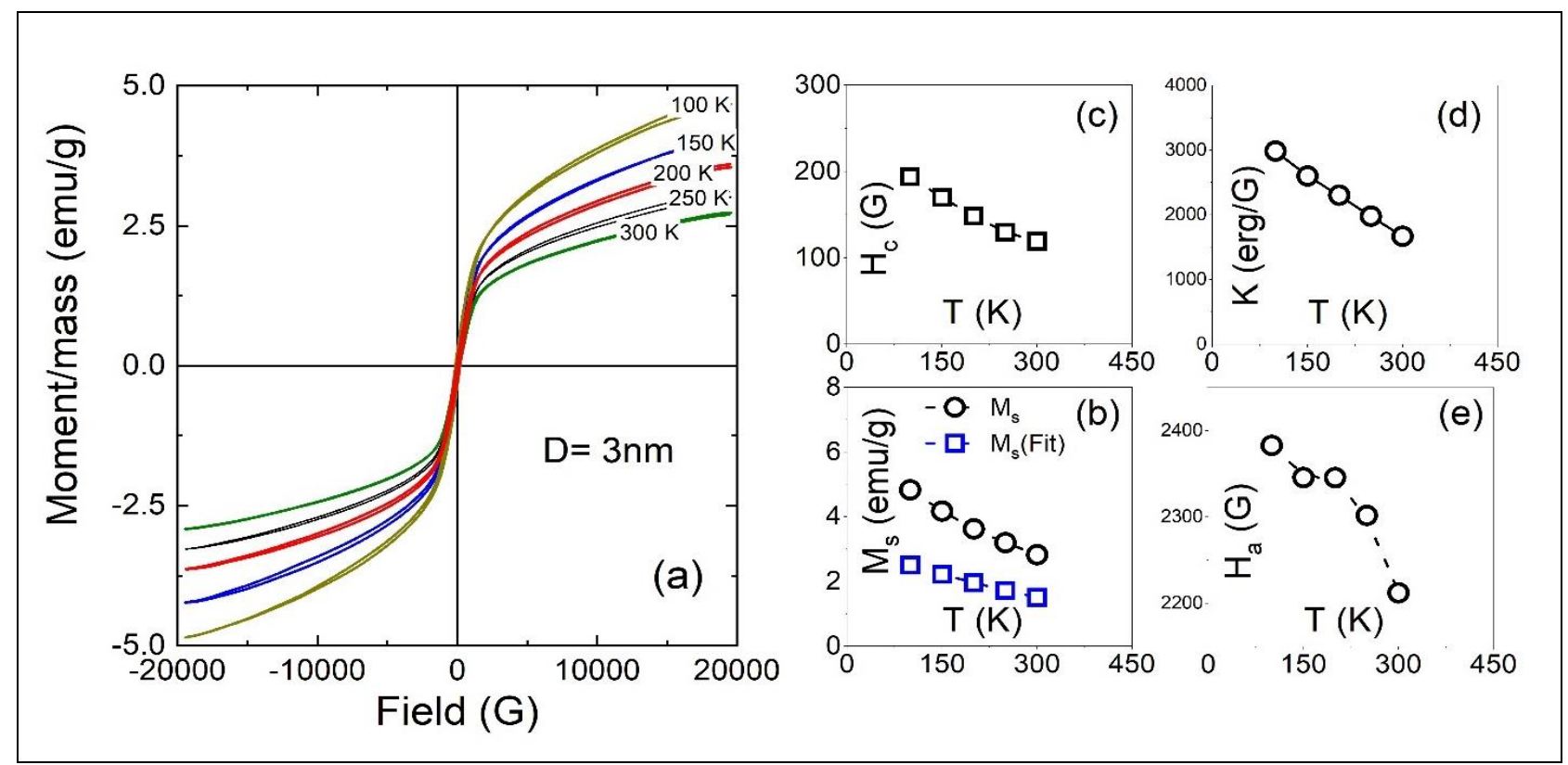

Fig. (11): a) Hysteresis loops at different temperatures, b) $M_{s}$, and $M_{s}($ Fit), c) coercivity (H), d) effective magnetic anisotropy constant $(\mathrm{K})$, and e) the anisotropy field $\left(\mathrm{H}_{\mathrm{a}}\right)$ for different $\mathrm{MgFe}_{2} \mathrm{O}_{4}$ samples

Table (5): The saturation magnetization $\left(M_{s}\right)$, coercivity $\left(H_{c}\right)$, remanent magnetization $\left(M_{r}\right)$, the squareness ratio $\left(R^{2}=M_{r} / M_{s}\right)$, observed moment $M_{o b s}$, and the parameters obtained from Eqs (16-18); Ms (Fit), effective magnetic anisotropy constant $(\mathrm{K})$ and the anisotropy field $\left(\mathrm{H}_{\mathrm{a}}\right)$ for $\mathrm{MF1}\left(\mathrm{MgFe}_{2} \mathrm{O}_{4}, \mathrm{D}=3 \mathrm{~nm}\right)$ sample at different temperatures

\begin{tabular}{cccccccccc}
\hline $\mathbf{T}$ & $\begin{array}{c}\mathbf{M}_{\mathbf{s}} \\
(\mathbf{K})\end{array}$ & $\begin{array}{c}\mathbf{H}_{\mathbf{c}} \\
(\mathbf{e m u} / \mathbf{g})\end{array}$ & $\begin{array}{c}\left.\mathbf{M}_{\mathbf{r}}\right) \\
(\mathbf{( e m u} / \mathbf{g})\end{array}$ & $\mathbf{R}^{2}=\mathbf{M}_{\mathbf{r}} / \mathbf{M}_{\mathbf{s}}$ & $\begin{array}{c}\mathbf{M}_{\mathbf{s}} \\
\left(\boldsymbol{\mu}_{\mathbf{B}}\right)\end{array}$ & $\begin{array}{c}\mathbf{M}_{\mathbf{s}}(\mathbf{f i t}) \\
(\mathbf{e m u} / \mathbf{g})\end{array}$ & $\chi_{\mathbf{0}}$ & $\begin{array}{c}\mathbf{K} \\
(\mathbf{e r g} / \mathbf{G})\end{array}$ & $\begin{array}{c}\mathbf{H}_{\mathbf{a}} \\
(\mathbf{G})\end{array}$ \\
\hline $\mathbf{1 0 0}$ & 4.8268 & 193.87 & 0.4405 & 0.09126 & 0.17284 & 2.5 & $1.3 \mathrm{E}-4$ & 2982 & 2383 \\
$\mathbf{1 5 0}$ & 4.1668 & 169.79 & 0.3402 & 0.08165 & 0.14921 & 2.21 & $1 \mathrm{E}-4$ & 2597 & 2346 \\
$\mathbf{2 0 0}$ & 3.6195 & 148.33 & 0.25632 & 0.07082 & 0.12961 & 1.96 & $9 \mathrm{E}-5$ & 2301 & 2346 \\
$\mathbf{2 5 0}$ & 3.194 & 129.51 & 0.19766 & 0.06188 & 0.11437 & 1.72 & $8 \mathrm{E}-5$ & 1979 & 2302 \\
$\mathbf{3 0 0}$ & 2.8275 & 119.11 & 0.16684 & 0.05901 & 0.10125 & 1.51 & $7 \mathrm{E}-5$ & 1667 & 2212 \\
\hline
\end{tabular}

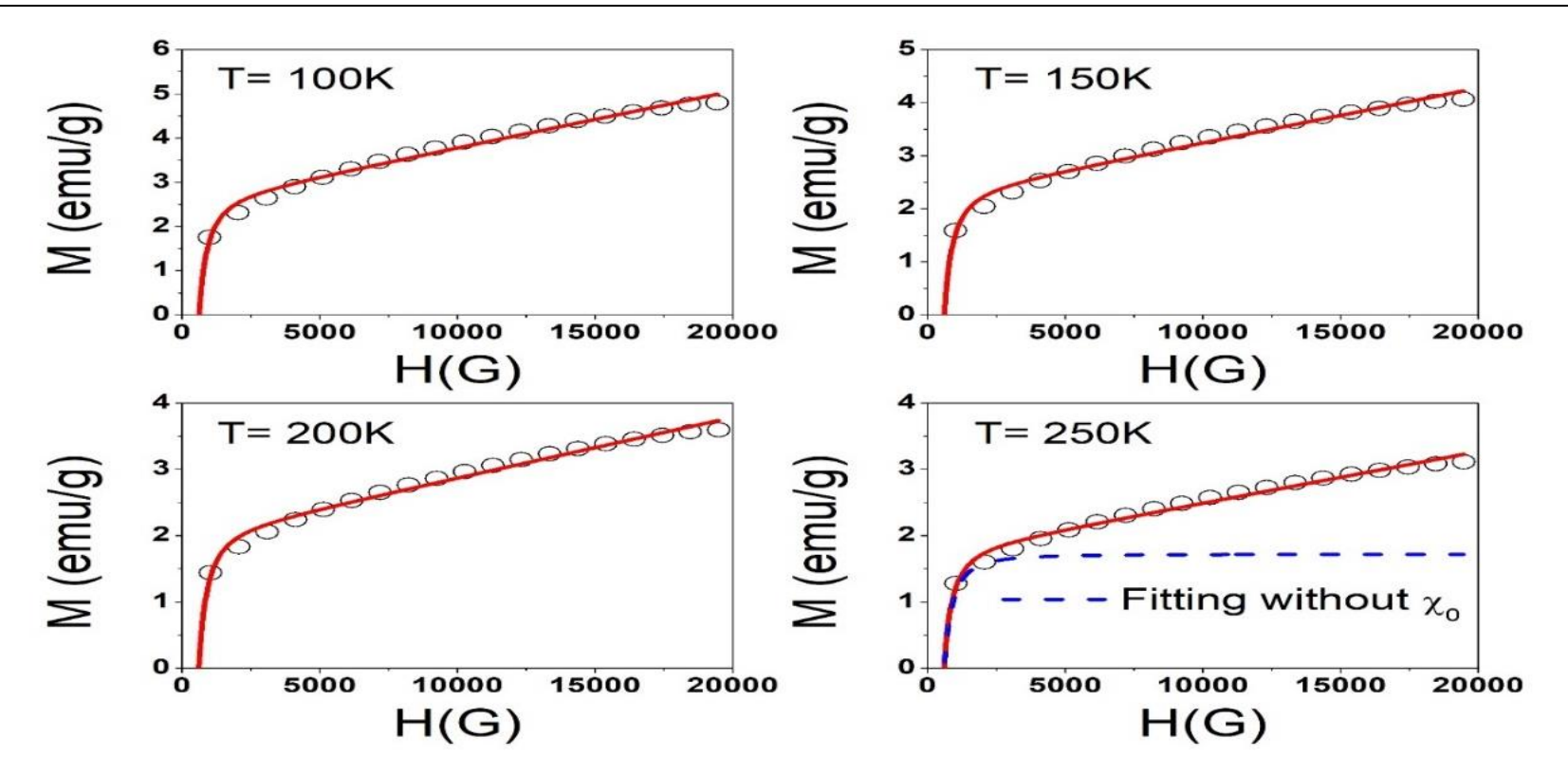

Fig. (12): The fitting of $M(H)$ of $M F 1$ sample with $D=3 n m$ at different temperatures according to Eq. (18) 


\section{CONCLUSION}

$\mathrm{MgFe}_{2} \mathrm{O}_{4}$ ferrite nanoparticles were synthesized in the sol-gel autocombustion method. XRD patterns confirmed the formation of the pure face center cubic structure. The particle size (D) was found to depend critically on the acidity of the preparation solution. For different $\mathrm{pH}$ values, 5, 7, and 8 , three different samples were obtained MF1 $(D=3 n m), M F 2(D=37)$, and MF3 $(D=48)$, respectively. The particle size was calculated using the Maud software and the Williamson-Hall (W-H) plots, and the obtained values showed good agreement. The lattice parameter $(a)$ decreased gradually with decreasing the particle size. The microstrain changed from a negative value for MF1 (3nm) to positive values for the other two samples, which suggest a strain for MF1, and tensile strain for MF2 and MF3. The particle size observed at the Transmission electron microscope (TEM) images showed good agreement with that calculated from the XRD measurements. Weak particle size dependence was observed for the elastic parameters. However, the D dependence of different elastic moduli is similar to the D dependence of the microstrain. The magnetic properties of the studied $\mathrm{MgFe}_{2} \mathrm{O}_{4}$ nanoparticles strongly depend on the particle size. The $\mathrm{M}(\mathrm{H})$ curves, at room temperature $(300 \mathrm{~K})$, were fitted and different magnetic parameters were obtained. The saturation magnetization and coercivity gradually increase by increasing the particle size, which illustrates that the particle size of the studied samples is below the single domain limit $\mathrm{D}_{\mathrm{c}}$. The effective magnetic anisotropy constant $(\mathrm{K})$ and anisotropy field $\left(\mathrm{H}_{\mathrm{a}}\right)$ showed a considerable $\mathrm{D}$ dependence. The magnetic hysteresis loops were measured at different temperatures $(\mathrm{T}=100 \mathrm{~K}, 150 \mathrm{~K}, 200 \mathrm{~K}, 250 \mathrm{~K}$, and $300 \mathrm{~K})$ for MF1. The saturation magnetization, the coercivity, the effective magnetic anisotropy constant, and the anisotropy field showed a significant temperature dependence, which might indicate that the MF1 sample has a particle size below the superparamagnetic limit $\mathrm{D}_{\mathrm{sp}}$

\section{REFERENCES}

[1] Phumying, Santi, Labuayai, Sarawuth, Swatsitang, Ekaphan, Amornkitbamrung, Vittaya, Maensiri, Santi, Nanocrystalline spinel ferrite $\left(\mathrm{MFe}_{2} \mathrm{O}_{4}, \mathrm{M}=\right.$ $\mathrm{Ni}, \mathrm{Co}, \mathrm{Mn}, \mathrm{Mg}, \mathrm{Zn}$ ) powders prepared by a simple aloe vera plant-extracted solution hydrothermal route, Materials Research Bulletin 48 (2013) 20602065.

[2] Sivakumar, N., Narayanasamy, A., Greneche, J. M., Murugaraj, R., Lee, Y. S., Electrical and magnetic behaviour of nanostructured $\mathrm{MgFe} 2 \mathrm{O} 4$ spinel ferrite, Journal of Alloys and Compounds 504 (2010) 395-402.

[3] M. Yehia, S. M. Ismail, and M. B. Mohamed, "Synthesis and Characterization of Ultrasmall Nanocrystalline Zn-substituted Ni-Sm-Ga Ferrites," J. Supercond. Nov. Magn. 28 (2015) 3335-3342.

[4] Ali, T.M., Ismail, S.M., Mansour, S.F. et al. Physical properties of Al-doped cobalt nanoferrite prepared by citrate-nitrate auto combustion method. J Mater Sci: Mater Electron 32 (2021) 3092-3103.

[5] Blanco-Gutiérrez, V., Climent-Pascual, E., SáezPuche, R., Torralvo-Fernández, María J., Temperature dependence of superparamagnetism in $\mathrm{CoFe}_{2} \mathrm{O}_{4}$ nanoparticles and $\mathrm{CoFe}_{2} \mathrm{O}_{4} / \mathrm{SiO}_{2}$ nanocomposites, Phys. Chem. Chem. Phys. 18 (2016) 9186-9193.

[6] Goodarz Naseri, Mahmoud Ara, Mohammad Hossein Majles Saion, Elias B., Shaari, Abdul Halim, Superparamagnetic magnesium ferrite nanoparticles fabricated by a simple, thermal-treatment method, Journal of Magnetism and Magnetic Materials 350 (2014) 141-147.

[7] S. Ilhan, S.G. Izotova, A.A. Komlev, Synthesis and characterization of $\mathrm{MgFe}_{2} \mathrm{O}_{4}$ nanoparticles prepared by hydrothermal decomposition of co-precipitated magnesium and iron hydroxides, Ceramics International 41 (2015) 0272-8842.

[8] Q. Chen, A.J. Rondinone, B.C. Chakoumakos, Z. John Zhang, Synthesis of superparamagnetic $\mathrm{MgFe}_{2} \mathrm{O}_{4}$ nanoparticles by coprecipitation, J. Magn. Magn. Mater. 194 (1999) 1-7.

[9] A. Pradeep, P. Priyadharsini, G. Chandrasekaran, Sol-gel route of synthesis of nanoparticles of $\mathrm{MgFe}_{2} \mathrm{O}_{4}$ and XRD, FTIR and VSM study, J. Magn. Magn. Mater, 320 (2008) 2774-2779.

[10] P. Holec, J. Plocek, D. Nižňanský, J. Poltierová Vejpravová, Preparation of $\mathrm{MgFe}_{2} \mathrm{O}_{4}$ nanoparticles by microemulsion method and their characterization, J. Sol-Gel Sci. Technol. 51 (2009) 301-305.

[11] J. Chandradass, K.H. Kim, Solvent effects in the synthesis of $\mathrm{MgFe}_{2} \mathrm{O}_{4}$ nanopowders by reverse micelle processing, J. Alloy Compd, 509 (2011), L59-L62.

[12] Y. Huang, Y. Tang, J. Wang, Q. Chen, Synthesis of $\mathrm{MgFe}_{2} \mathrm{O}_{4}$ nanocrystallites under mild conditions Mater. Chem. Phys, 97 (2006) 394-397. 
[13] V. Šepelák, I. Bergmann, D. Menzel, A. Feldhoff, P. Heitjans, F.J. Litterst, K.D. Becker. Magnetization enhancement in nanosized $\mathrm{MgFe}_{2} \mathrm{O}_{4}$ prepared by mechanosynthesis, J. Magn. Magn. Mater, 316 (2007), e764-e767.

[14] V. Šepelák, D. Schultze, F. Krumeich, U. Steinike, K.D. Becker, Mechanically induced cation redistribution in magnesium ferrite and its thermal stability, Solid State Ionics, 141 (2001), 677-682.

[15] S. Maensiri, M. Sangmanee, A. Wiengmoon, Magnesium ferrite $\left(\mathrm{MgFe}_{2} \mathrm{O}_{4}\right)$ nanostructures fabricated by electrospinning, Nanoscale Res. Lett, 4 (2009), 221-228.

[16] T. Sasaki, S. Ohara, T. Naka, J. Vejpravova, V. Sechovsky, M. Umetsu, S. Takami, B. Jeyadevan, T. Adschiri, Continuous synthesis of fine $\mathrm{MgFe}_{2} \mathrm{O}_{4}$ nanoparticles by supercritical hydrothermal reaction, J. Supercrit. Fluid 53 (2010), pp. 92-94

[17] M. Ferrari and L. Lutterotti, "Method for the simultaneous determination of anisotropic residual stresses and texture by x-ray diffraction, J. Appl. Phys. 76 (1994) 7246-7255.

[18] M. Yehia, S. M. Ismail, and M. B. Mohamed, "Synthesis and Characterization of Ultrasmall Nanocrystalline Zn-substituted Ni-Sm-Ga Ferrites," J. Supercond. Nov. Magn. 28 (2015) 3335-3342.

[19] M. Satalkar, S.N. Kane, On the study of structural properties and cation distribution of $\mathrm{Zn}_{0.75}$ ${ }_{x} \mathrm{Ni}_{x} \mathrm{Mg}_{0.15} \mathrm{Cu}_{0.1} \mathrm{Fe}_{2} \mathrm{O}_{4}$ nano ferrite: effect of $\mathrm{Ni}$ addition. J. Phys. 755 (2016) 012050.

[20] H. Irfan, M. Racik, S. Anand, Microstructural evaluation of $\mathrm{CoA} 12 \mathrm{O} 4$ nanoparticles by Williamson-Hall and size-strain plot methods. J. Asian Ceramic Soc. 6 (2018) 54-62.

[21] Routray, Krutika L., Saha, Sunirmal, Behera, Dhrubananda, Rare-earth (La3+) substitution induced changes in the structural, dielectric and magnetic properties of nano- $\mathrm{CoFe}_{2} \mathrm{O}_{4}$ for highfrequency and magneto-recording devices,
Applied Physics A: Materials Science and Processing 125 (2019) 1-15.

[22] M. Deepty, Ch. Srinivas, E. Kumar, N. Ranjith Mohan, C.L. Krisha Prajapat, T.V. Chandrasekhar Rao, S.S. Meena, A.K. Verma, D.L. Sastry, XRD, EDX, FTIR and ESR spectroscopic studies of coprecipitated Mn-substituted Zn-ferrite nanoparticles. Ceram. Int. 45 (2019) 8037-8044.

[23] K. V. Chandekar and K. M. Kant, "Estimation of the spin-spin relaxation time of surfactant coated $\mathrm{CoFe} 2 \mathrm{O} 4$ nanoparticles by electron paramagnetic resonance spectroscopy," Phys. E LowDimensional Syst. Nanostructures 104 (2018) 192205.

[24] A. V. Anupama, V. Rathod, V. M. Jali, and B. Sahoo, Composition dependent elastic and thermal properties of Li-Zn ferrites, J. Alloys Compd. $\mathbf{7 2 8}$ (2017) 1091-1100.

[25] R. D. Waldron, Infrared Spectra of Ferrites, Phys. Rev. 99 (1995) 1727-1735.

[26] K. B. Modi, M. K. Rangolia, M. C. Chhantbar, and H. H. Joshi, Study of infrared spectroscopy and elastic properties of fine and coarse grained nickelcadmium ferrites, J. Mater. Sci. 41 (2006) 7308 7318.

[27] Prasad, S. A.V., Deepty, M., Ramesh, P. N., Prasad, G., Srinivasarao, K., Srinivas, Ch, Vijaya Babu, K., Ranjith Kumar, E., Krisha Mohan, N., Sastry, D. L., Synthesis of $\mathrm{MFe}_{2} \mathrm{O}_{4}\left(\mathrm{M}=\mathrm{Mg}^{2+}, \mathrm{Zn}^{2+}, \mathrm{Mn}^{2+}\right)$ spinel ferrites and their structural, elastic and electron magnetic resonance properties, Ceramics International 44 (2018) 10517-10524.

[28] M. Yehia, A. Hashhash, Structural and magnetic study of $\mathrm{Sm}$ doped $\mathrm{NiFe}_{2} \mathrm{O}_{4}$ nanoparticles, Journal of Materials Science: Materials in Electronics 30 (2019) 6768-6775.

[29] Caizer C. Nanoparticle Size Effect on Some Magnetic Properties. In: Aliofkhazraei M. (eds) Handbook of Nanoparticles. Springer, Cham. (2015). 